\title{
A Geografia na Obra de Júlio Verne: difusão, tradição e modernidade
}

\author{
Inês Aguiar de Freitas ${ }^{1} \&$ Rodrigo Fernandes ${ }^{2}$ \\ ${ }^{1}$ Doutora em Geografia pela Université de Paris IV - Sorbonne. Professora Associada do Departamento de Geografia Humana do \\ Instituto de Geografia (IGEOG) e do Programa de Pós-Graduação em Geografia da Universidade do Estado do Rio de Janeiro - \\ UERJ.E-mail: freitasines@bol.com.br \\ ${ }^{2}$ Aluno de Graduação em Geografia e Bolsista PIBIC / UERJ do Instituto de Geografia (IGEOG) da Universidade do Estado do Rio de \\ Janeiro - UERJ.E-mail: oficinadaspalavras@yahoo.com.br
}

Recebido em 04/2012. Aceito para publicação em 12/2012.

Versão online publicada em 01/02/2013 (http://seer.ufrgs.br/paraonde)

\begin{abstract}
Resumo - Utilizando-nos apenas de algumas das obras de Verne a título de exemplo, teremos entre nossos objetivos, neste trabalho, destacar alguns temas, características e elementos da geografia presentes nas obras de Verne que nos dão provas da enorme preocupação que este autor conferiu à geografia e aos temas relacionados à nossa disciplina. Podemos destacar três características na obra de Verne, no que tange a geografia: 1) A preocupação com a natureza da geografia e com o papel do geógrafo. Assim, nossa principal contribuição neste trabalho será investigar essas duas preocupações que parecem curiosamente incomuns entre aquelas que atraem um escritor de ficção, uma vez que concernem à história do pensamento geográfico mais especificamente; 2) A não inscrição de sua obra em uma determinada Escola do Pensamento Geográfico; 3) A situação de trabalhar dentro de uma "geografia antes da geografia", mas, ao mesmo tempo prever o nascimento de uma geografia moderna. Trataremos ainda da obra de Verne sob dois aspectos: o divulgador científico e o visionário. Como divulgador da geografia que se fazia em sua época, os exemplos são muitos em toda a sua obra e se encontram no cotidiano de seus personagens. Como visionário, não lhe escapou nem mesmo a previsão do nascimento da geografia moderna. Podemos dizer que Júlio Verne fez da ciência uma presença viva em todas as suas obras e que encontrou na "verdadeira" geografia a certeza de estar escrevendo sobre a maior das aventuras humanas - a conquista da Terra.
\end{abstract}

Palavras-chaves: Júlio Verne. Pensamento Geográfico. Literatura e Geografia.

"Tinha a expressão atenta e séria de um rapaz lendo um livro de Júlio Verne."

Marcel Proust

\section{Introdução}

No âmbito de um encontro como este, dedicado à geografia e suas relações com a música e a literatura, cremos não poder faltar uma intervenção sobre a geografia presente na obra do romancista francês Júlio Verne (1828 - 1905). Autor de obras de ficção, voltadas para o público infantojuvenil, Verne dispensa maiores apresentações.

Por isso mesmo, o presente trabalho não tem a pretensão de ser inédito, pois devemos crer na existência, principalmente na França, de trabalhos que já tenham se ocupado da análise da obra de Júlio Verne à luz da geografia e sob os mais diversos aspectos, especialmente os que tratam de análises literárias. Porém, entre os geógrafos (brasilei- ros, especialmente), não temos conhecimento de um trabalho que tenha nos servido de guia aos temas que aqui pretendemos, mais do que conseguir desenvolver, antes, colocar em discussão.

Utilizando apenas algumas das obras de Verne a título de exemplo (já que os limites impostos a um trabalho a ser apresentado num encontro nos impedem uma análise detalhada ou mais minuciosa de uma obra que é vastíssima), teremos entre nossos objetivos destacar alguns temas, características e elementos da geografia presentes nas obras de Verne que nos dão, não somente provas da enorme preocupação que este autor conferiu à geografia e aos temas relacionados com nossa disciplina, mas que também nos parecem curiosamente incomuns entre as preocupações de um escritor de ficção.

Está claro que há, em Verne, uma verdadeira paixão (fixação) pelos temas e elementos geográficos, porém, numa perspectiva que vai muito 
além da que seria esperada em um escritor de ficção, o autor trata de questões muito ligadas à história do pensamento geográfico, ao papel do geógrafo e à natureza da geografia.

Ao mesmo tempo em que, ao contrário da utilização de "geografias de lugares imaginários" (como o fez, por exemplo, J. R. Tolkien em seu "O Senhor dos Anéis") ou utilizando-se de "imaginações geográficas", Júlio Verne tem na "verdadeira" geografia a base de suas obras e a certeza de estar escrevendo sobre a maior das aventuras humanas - a conquista da Terra.

\section{Júlio Verne - divulgador científico e visionário}

Julio Verne, em sua extensa obra bibliográfica, talvez tenha, como nenhum outro ficcionista do cânone literário, se apropriado da ciência geográfica em seu ofício. No universo verniano encontramos a Geografia tomada como cenário de suas aventuras e como um poderoso zeitgeist que imbui e galvaniza seus personagens rumo à descoberta de novos espaços, paisagens e concepções do mundo.

Porém, classificar o escritor francês como um autor de ficções geográficas seria uma visão reducionista. Em sua produção, Verne transita entre duas dimensões distintas - ainda que intercambiáveis - colocando-se como "ponte" entre elas: o passado e o futuro. Entre o conquistado e o por se conquistar. J. Verne apresenta-se tanto como um divulgador apaixonado de todo conhecimento geográfico acumulado até então, quanto um visionário que anteviu, com um notável grau de precisão, as propostas, demandas e possibilidades de uma geografia nova, uma geografia moderna.

Na introdução de "Os Navegadores do Século XVIII" (1878) o autor nos fornece uma pista de sua missão de divulgador científico. A diretriz traçada pelo escritor não poderia ser expressa de forma mais explícita.

Antes de encetar a narrativa das grandes expedições do século XVIII devemos apontar os imensos progressos realizados pelas ciências durante este período (VERNE, 1878.).

É ainda importante observar que o escritor não se atinha à mera discrição dos grandes feitos e descobertas científicas. Sua divulgação possuía um caráter surpreendentemente crítico quanto ao uso e a apropriação da ciência pelo homem e para o homem, antecipando em ao menos um século a criticidade que hoje é inerente a qualquer fazer científico razoavelmente criterioso. Apesar da sua celebração do conhecimento, há em Verne sempre uma advertência.

Apesar de Galileu ter observado em 1610 os eclipses dos satélites de Júpiter, a indiferença dos governos, a falta de instrumentos de bastante força, os erros cometidos pelos discípulos do grande astrônomo italiano, tinham tornado estéril esta importante descoberta. (Ibid.)

À vista disso, Muniz Sodré, numa rara investigação "nacional" sobre os autores de ficção científica, considera que:

Em Verne, o conhecimento implica em abertura, que por sua vez implica em erro humano. $O$ saber e a falta estão associados (...) Numa época que a ciência substituía Deus na História, a ficção verniana denunciava assim a sua perfectibilidade como morte ou entropia (previsibilidade absoluta) e assentava no humano - a falha do sábio - o princípio da descoberta e da vida. Em Verne, o otimismo da superfície vira desconfiança na estrutura. (SODRÉ, 1973)

Ainda em "Os Navegadores do Século XVIII" (1878), Verne narra uma série de aventuras empreendidas pelos grandes cientistas e exploradores daquele período. 0 leque é amplo, e o escritor sente-se obrigado a fazer justiça a todos. Cita de Cassine a Bouganville, passando por Picard, Surville, Marion, Marchand e Cook. E se os homens que se empenharam no alargamento das fronteiras do conhecimento têm de ser celebrados por seus feitos, nem mesmo o próprio fluxo da história da ciência geográfica lhe escapa. Não é, portanto nenhum exagero afirmar que o mestre francês foi também um pioneiro historiador da geografia. Ele mostrase atento não somente aos avanços, mas também aos seus retrocessos epistemológicos. As primeiras linhas de "Os exploradores do Século XIX" (1878) não nos deixam dúvidas.

o fim do século XVIII e o princípio do século XIX distinguem-se por um sensível esmorecimento das grandes descobertas geográficas. (VERNE, 1878)

Portanto, nos é bastante claro que, apesar de ter sido absorvido, deglutido e classificado pelo cânone cultural ocidental como um autor de ficções utópicas, a obra de Verne é de caráter eminentemente cientificista, didático, e, mais especificamente, geográfico. A descrição de fenômenos, 
como exemplificado em “O País das Peles” (1873) é uma constante em sua obra.

Entretanto a pequena expedição chega-
ra a vinte e três de maio, após jornadas
extensas e fatigantes, aos limites do
círculo polar. É sabido que este paralelo,
afastado $23^{\circ} 27^{\prime} 57^{\prime \prime}$ do Polo Norte,
forma o limite matemático ao qual che-
gam os raios solares, quando o astro
radioso descreve a sua órbita no hemis-
fério oposto. Portanto, a partir daquele
ponto, entrava deveras o destacamento
nas regiões árticas propriamente ditas.
(VERNE, 1873)

No discurso verniano a ciência não apenas ilumina a ficção, mas a ofusca. Por vezes, o didatismo científico parece mesmo invadir e subjugar a literatura. A dicção literária fica de lado e dá lugar uma direta e acurada descrição geográfica. Em "Fora dos Eixos" (1889), parecemos estar diante não de um livro de ficção, mas de um ensaio científico.

As terras árcticas, propriamente ditas, compreendem, segundo Malte-Brun, Réclus, Saint-Martin e os mais autorizadosgeógrafos.

1 - O Devon Setentrional, isto é, as ilhas, cobertas de gelo, do mar de Baffin e do estreito de Lancastre;

2ํ - A Jórgia Setentrional, constituída pela terra de Banks e numerosas ilhas, tais como as Sabinas, Biam - Martim, Griffith, Cornwallis e Bathurst;

3o - O Arquipélago de Baffin-Pang, compreendendo diversas porções do continente circumpolar chamadas Cumberland, Southampton, James-Sommerset. Boothia-Felix, Melville e outras quase desconhecidas.

Neste conjunto, limitado pelo $78^{\circ}$ paralelo, as terras têm uma superfície de um milhão e quatrocentas milhas e os mares setecentas mil milhas quadradas. (VERNE, 1889)

Como já afirmamos, os exemplos do uso da ciência geográfica na obra do escritor são numerosos e convincentes. Lembremo-nos ainda da biblioteca situada no centro do submarino Nautilus, de "Vinte Mil Léguas Submarinas" (1870), onde se encontrava a obra completa de Humboldt; ou ainda, de sua paixão pelos estudos científicos e geográficos das grandes viagens de descobrimento e suas descobertas ${ }^{3}$.

Tais exemplos reafirmam que, tanto quanto a ficção, é a ciência o grande leitmotiv de Verne. Não por acaso o autor é considerado por muitos um dos criadores de uma ficção nomeada científica ("Science Fiction" ou "Scientific Romance", como preferia H.G.Wells, o outro "pai" do estilo). E no momento em que prevê as missões espaciais, a exploração submarina e inventos como a televisão, o cinema falado, o submarino, os foguetes espaciais, o arcondicionado, os arranha-céus e os veículos anfíbios (nos detendo aqui num inventário bem modesto do que o escritor anteciparia), J. Verne deixa de ser um ficcionista e um divulgador da ciência para tornar-se um visionário. Alguém com tanta devoção (ainda que desconfiada) no desenvolvimento científico que passa a descrever não apenas o que a ciência já é, mas o que pode vir a ser. Não mais o que a ciência já conquistou, mas o que ela conquistará. Paradoxalmente, a despeito de suas "visões" do futuro, Verne era um realista. Sem renunciar seu tempo histórico, o autor de "Viagem ao Centro da Terra" não blefa com o futuro em sua pedagogia da antecipação. Antes fndamenta sua escrita em pesquisas exaustivas e consultas com cientistas. Tornar-se-á, portanto, a antítese daquilo que Schopenhauer, seu contemporâneo, defendia em seu "O Mundo Como Vontade e Representação” (1819).

as ciências naturais, ao desenvolveremse, acabam sempre por tropeçar em qualidades ocultas. A cuja categoria pertencem as forças elementais da natureza, as quais, por isso mesmo, competem à filosofia e não à ciência. (SCHOPENHAUER, 1819)

Seus heróis não são simples aventureiros, muito menos peregrinos místicos, são, antes, homens da ciência: Matemáticos (J. T. Maston de "Fora dos Eixos" e "À roda da Lua"), geólogos (Dr. Otto Lidenbrock de "Viagem ao Centro da Terra"), engenheiros (Cyrus Smith de "A Ilha Misteriosa") e Naturalistas (Professor Aronnax de "Vinte Mil Léguas Submarinas"). E o célebre Capitão Nemo? Seria ele a reunião de todos esses cientistas e o Nautilus a materialização da própria ciência como ferramenta que permite ao homem descer às abissais profundidades do desconhecido? A visão de um Capitão Nemo, pensativo, observando o inóspito fundo do oceano pela escotilha do seu submarino é boa demais para ser descartada como metáfora do poder da ciência em iluminar o Mistério.

Elegendo e enobrecendo homens da razão, 
Verne subverte o estereótipo de herói clássico, aquele que supera seus desafios com força, bravura e a lâmina de uma espada. A carruagem e o cavalo são trocados pelo que há de mais moderno. 0 balão, o foguete, o submarino. Máquinas. Verne desencanta a ludicidade das novelas de cavalaria e transporta o homem à lua, roubando-lhe o mistério e a magia. Em seus livros as grandes virtudes heroicas são o conhecimento, a razão, e, claro, a curiosidade. A própria grande aventura não é mais desafiar os deuses, salvar a amada das garras do malfeitor ou recuperar o reino do invasor sinistro. A missão agora é desvendar, conhecer, descobrir e, indiretamente, enriquecer a biblioteca do conhecimento humano.

Como visionário, dentre todas as "previsões" que fez (a maior parte delas realizadas), temos que dar destaque, como geógrafos, ao verdadeiro tratado de urbanismo (e de geografia urbana) que escreveu, apontando os problemas (e soluções) de uma superpovoada e fervilhante Paris no século XX. (É o tema de "Paris no século XX" (1863), obra póstuma cujos manuscritos foram encontrados e vieram a ser publicados em 1989).

Divulgador e visionário - é revelador que a Editora Paulo de Azevedo (Rio de Janeiro) em conjunto com a Livraria Bertrand (Lisboa) publicam, em português, por volta de 1950, a obra completa de Verne numa coleção que leva o título de "Grande Edição Popular das Viagens Maravilhosas aos Mundos Conhecidos e Desconhecidos".

\section{As exóticas preocupações de Verne com a geo- grafia}

No entanto, como dissemos acima, alguns elementos da geografia em Verne o diferem dos demais autores e até mesmo de escritorescientistas ("geógrafos do rei", "viajantes-naturalistas" etc.) responsáveis pelas ciências naturais em algum momento da história. Queremos analisar, neste momento, três peculiares características que chamam a atenção numa análise geográfica de sua obra. Seriam elas:

1) A preocupação com a natureza da geografia e o papel do geógrafo - elementos sempre presentes em nossas discussões acadêmicas sobre a formação do pensamento geográfico;

2) A não inscrição de sua obra em um momento específico da História da Geografia, ou, se preferirmos, em uma determinada Escola do Pensamento Geográfico (mesmo porque nossa ciência, em sua época, apenas nascia como disciplina acadêmica); mas, por outro lado, sua inscrição em várias "tradições geográficas" apontadas por

\section{Livingstone (1992) ;}

3) A situação dos elementos, conhecimentos e temas geográficos dentro de um "pensamento geográfico" que tem sua origem naquilo que podemos chamar de uma "geografia antes da geografia moderna", ou seja, que antecede a geografia tal como hoje a praticamos; ao mesmo tempo em que aponta para o nascimento de uma geografia moderna: um saber com métodos, objeto e uma certa coerência interna (e tem consciência disto, pois faz com que seus personagens a pratiquem!). Enfim, trata a geografia como uma ciência, num exercício visionário do que nossa disciplina viria a ser!

Vejamos cada uma dessas características mais detalhadamente.

A primeira característica que podemos destacar é a importância que Júlio Verne concerne ao papel do geógrafo entre os demais cientistas, dando-nos o papel que a modernidade nos conferiu: o de organizadores do espaço geográfico, o de conhecedores da Terra, com a tarefa de descrever o mundo. Poucos autores (geógrafos inclusive) tiveram tanta clareza ao definir o que é ser geógrafo e qual a natureza de nossa ciência como nestes trechos retirados de "A Ilha Misteriosa" (VERNE, 1873-75):

Quanto a mim - disse o marinheiro - que perca o meu nome se me agastar com o trabalho, e se quiser, Sr. Smith, faremos desta ilha uma pequena América! Construiremos cidades, criaremos caminhosde-ferro, instalaremos telégrafos, e um belo dia, quando ela estiver bem transformada, bem ordenada, bem civilizada, iremos oferecê-la ao Governo da União! Apenas peço uma coisa.

-Qual?-respondeu o repórter.

- É de não mais nos considerarmos como náufragos, mas sim como colonos que vieram aqui para colonizar!

Cyrus Smith não pôde deixar de sorrir e a ideia do marinheiro foi adotada. (...)

- Meus amigos, respondeu o engenheiro, me parece bom dar um nome a esta ilha, assim como aos cabos, aos promontórios, aos cursos d'água que temos sob os olhos...

- Muito bom, disse o repórter. Isso simplificará no futuro as instruções que poderemos ter a dar ou a seguir.

- Com efeito, replicou o marinheiro, já é alguma coisa poder dizer onde se vai ou de onde se vem. Ao menos, tem-se a impressão de estar em algum lugar...

A proposta do engenheiro foi unanimemente aceita por seus companheiros. (E, 
após ter sido batizada)... A ilha estava lá, sob seus olhos, como uma carta desdobrada, e tudo o que havia era um nome a colocar em todos os seus ângulos entrando ou saindo, como em todos os seus relevos. Gédéon Spilet (o geógrafo) os escreveria à medida em que eles aparecessem e a nomenclatura geográfica da ilha seria definitivamente adotada.(VERNE, 1873-75)

A natureza da geografia, para Verne, é a de dar ao homem a posse da Terra. Seus personagens deixam de ser náufragos e passam a ser "colonos", a partir desse ato de denominar/dominar o mundo, "transformando a ilha num "mapa desdobrado, fazendo do seu território um mapa que se pode manipular, que se pode ler e sobre o qual se pode ler a si próprio: ...colonizar é transformar um espaço qualquer em lugar". (FREITAS, 1998, p.27)

Se, transformar a Terra no lugar do homem, em território dominado, seria, para ele, a natureza da geografia moderna, o papel do geógrafo "moderno" seria o de nomear, descrever, classificar.

A segunda característica da obra de J. Verne por nós apontada é a de que não poderíamos inscrevê-la, ou aprisioná-la dentro de qualquer Escola do pensamento geográfico tal como este tem sido classificado tradicionalmente no Brasil, a partir da geografia francesa / europeia de uma maneira geral. Mesmo porque, nossa ciência mal nascia entre as ciências modernas. Porém, é nítido que Verne e sua visão da geografia se classificaria muito mais no conjunto de "tradições geográficas" como as propostas por David Livingstone (1992, 1992a).

Este autor acredita que a geografia tem significado coisas diferentes para pessoas diferentes. Assim, não existiria apenas uma "história da geografia", mas histórias de diversas tradições que se sobreporiam, se misturariam e se alternariam, em momentos diferentes, em sociedades diferentes ou em ambientes diferentes, formando aquilo que nós, enfim, conhecemos por "geografia". Poderíamos traçar um perfil das "tradições geográficas", sabendo que sua existência se opõe à construção de uma história linear da geografia e observarmos (facilmente) como e quanto dessas tradições estão contempladas na obra de Verne.

Utilizando denominações que o próprio Livingstone criou, observamos, por exemplo, a existência de uma "geografia mágica" para falar da geografia mística, ligada à astrologia, à magia natural (que se praticava na Antiguidade), mas também do conhecimento da Terra como magia, da ciência e do conhecimento como "poder"; propõe também a ideia de um "mundo de papel", para designar a tra- dição cartográfica sempre assumida como uma função e não como um instrumento da geografia; ou a tradição do "Universo como um relógio", para definir a tradição mecanicista do século XVIII; falanos ainda da tradição de viagens, presente entre os geógrafos, cujo desejo maior sempre foi o de ir "até o fim do mundo"; da tradição de uma geografia ligada à físico-teologia, praticada entre os sábios dos séculos XVIII e XIX e que fala da descoberta de Deus na observação da natureza; da geografia em sua tradição como instrumento do imperialismo no século XIX ("Geografia, raça e Império"); dos "rituais de regionalização" praticados desde os gregos e que alcançou seu apogeu no possibilismo de Vidal de la Blache, no início do século XX; da tradição de uma geografia funcionalista dos anos 1940-50; de "cada coisa em seu lugar" - que trata da geografia e sua tradição de "ciência do espaço"; da tradição estatística e da febre dos números que tomou conta de nossa ciência especialmente nos anos 1950-60 ("estatísticas não sangram"); do determinismo econômico que guiou a tradição marxista em nossa ciência nos anos 1970; e ainda da "fragmentação" e do pluralismo que nossa "geografia pós-moderna" nos exige, ao inaugurar mais uma nova tradição na geografia dos anos 1990.

Mas, em que "tradição geográfica" poderíamos inserir a obra de J. Verne? Poderíamos supor que, por contemporaneidade, "naturalmente" sua obra estaria inscrita na tradição "Geografia, Raça e Império". Seria um erro, e mesmo antes, um grande reducionismo de nossa parte, acreditar nisso. A obra de Verne se reconhece em muitas dessas tradições, como, obviamente a tradição de "Até o fim do mundo" - a tradição das viagens, tradição geográfica que resume toda a vontade de conhecer e explorar o mundo e de tudo desvendar (roteiro sempre presente no romancista francês) que move a maioria de seus personagens, falando da curiosidade e da surpresa diante da natureza e do mundo; ou "Geografia é mágica", ou "Um mundo de papel" ou mesmo o "Universo como um relógio". Como já dissemos, estas diversas tradições se misturam, se entrelaçam, se sobrepõem, se alternam e não se apresentam de maneira diferente ao longo das obras de Verne.

Quanto à terceira característica da geografia de Júlio Verne - a preocupação com que seus personagens praticassem uma "geografia moderna" está nítida no exemplo utilizado acima, no item 1, quando da divisão de trabalho na ilha entre os "náufragos", cabendo, naquele momento, ao geógrafo, a nomeação, a descrição, a organização do espaço. É exatamente no momento em que define o geógrafo moderno que Verne faz ver nascer a geo- 
grafia tal como hoje a conhecemos, a partir das preocupações apontadas por Moravia, referindose à geografia do fim do século XVIII:

As viagens, as pesquisas geográficas
devem assumir um rigor científico novo,
formado justamente sobre os critérios
epistemológicos mais caros dos ideólo-
gos: a descrição exata do que é visível, a
decomposição sensualista dos objetos
complexos em ideias simples - ou seja, a
descrição e a análise. (MORAVIA, 1967,
p. 940 )

Ou seja, para que os colonos pudessem aplicar seus conhecimentos no meio natural da ilha e transformá-los em benefícios em busca de sua sobrevivência, era necessário fazer duas coisas: em primeiro lugar, realizar o reconhecimento completo da ilha, identificar e inventariar os elementos que serviriam para transformar em instrumentos de sobrevivência, através da exploração da ilha. Estava clara a necessidade da utilização de um método apoiado em anotações, observações e análises.

E, afinado com seu tempo, Verne faz ainda com que seus personagens da "Ilha Misteriosa" se envolvam ativamente numa questão "geopolítica", dispostos a defender sua ilha a qualquer custo, até quando esta foi invadida por um grupo de piratas.

A propósito - replicou o marinheiro - $e$ aos seis patifes que erram na ilha, o que lhes faremos? Vamos deixá-los percorrer nossas florestas, os nossos campos, as nossas pradarias? São verdadeiros jaguares, esses piratas, e parece-me que não devemos hesitar em tratá-los como tais! (VERNE, 1875, p.176, vol.II)

\section{Últimas considerações}

Carl Sagan, o renomado e popular físico americano, disse em sua obra "O mundo Assombrado pelos Demônios: a ciência vista como uma vela no escuro" (1996) que a realidade vista através da ciência é sempre mais emocionante que qualquer forma de ficção. Apresentamos aqui, elementos que provam o mesmo em relação à geografia presente nas obras de Verne.

Júlio Verne não pensava diferente em seu papel de divulgador científico. Sim, porque se pode perceber que nosso autor não se ocupava apenas da geografia ou do saber geográfico, mas também se utilizava e fazia a crítica à produção científica de outros ramos do saber, como a astronomia, a geologia, a física e até mesmo a economia. Esta forma de divulgação da ciência, que embaseava muitos momentos de seus livros ou que constituía o cenário para diferentes personagens, leva a crer que também serviam como atrativos para sua literatura. Jovens, crianças e mesmo os adultos intuíam não estar lendo "qualquer coisa" e a leitura de Verne provavelmente conduziu a diversas vocações. Muitas delas talvez tenham levado à formação de companheiros de profissão aqui hoje presentes.

\section{Referências}

FREITAS, Inês A. A Natureza de uma Geografia Nova. GEOUERJ, 3: 27037, 1998.

Pour une histoire naturelle de la géographie: les voyageurs-naturalistes français aux Brésil au Siècle des Lumières. Tese de doutorado, Université de Paris IV - Sorbonne, 1992.

LIVINGSTONE, D. A brief History of Geography in ROGERS, A.; VILES, H. e GOUGIE, A. B. (eds.) The Students Companion to Geography. Oxford, Blackwel, 1992, p.27-35.

Blackwel, 1992a.

. The Geographical Tradition. Oxford,

MORAVIA, S. Philosophie et Géographie à la fin du XVIII siècle. Studies on Voltaire and the Eighteenth Century, LVIII, p. 937 - 1011.

SAGAN, Carl. O Mundo Assombrado pelos Demônios: a ciência vista como uma vela no escuro. São Paulo, Cia. Das Letras, 1996.

SCHOPENHAUER, Arthur. O Mundo Como Vontade e Representação. São Paulo. Editora UNESP, 2005.

SODRÉ, Muniz. A Ação do Tempo - análise da narrativa de Science-Fiction. Rio de Janeiro, Vozes, 1973,p.91-92.

VERNE, Júlio. Vinte Mil Léguas Submarinas. Rio de Janeiro/Lisboa. Editora Paulo de Azevedo /Livraria Bertrand. s/d.

VERnE, Júlio. A Ilha Misteriosa. Rio de Janeiro/Lisboa. Editora Paulo de Azevedo /Livraria Bertrand.s/d.

VERnE, Júlio. O País das Peles. Rio de Janeiro/Lisboa. Editora Paulo de Azevedo /Livraria Bertrand.s/d.

VERNE, Júlio. A Roda à lua. Rio de Janeiro/Lisboa. 
Editora Paulo de Azevedo /Livraria Bertrand. s/d.

VERNE, Júlio. Fora dos Eixos. Rio de Janeiro/Lisboa. Editora Paulo de Azevedo /Livraria Bertrand. s/d.

VERNE, Júlio. Os Navegadores do Século XVIII. Rio de Janeiro/Lisboa. Editora Paulo de Azevedo /Livraria Bertrand.s/d.

VERNE, Júlio. Os exploradores do Século XIX. Rio de Janeiro/Lisboa. Editora Paulo de Azevedo /Livra- ria Bertrand.s/d.

VERNE, Júlio. Viagem ao Centro da Terra. Rio de Janeiro/Lisboa. Editora Paulo de Azevedo /Livraria Bertrand. s/d.

BnF - Bibliothèque nationale de France - http:// data.bnf.fr/11928016/jules_verne/

Centre International Jules Verne - http:// www.jules-verne.net/\#

\title{
Geography in the work of Jules Verne: diffusion, tradition and modernity
}

\begin{abstract}
Using just a few of the works of Verne as an example, we have among our objectives in this paper highlight some themes, features and elements of geography in the works of Verne that give evidence of great concern that this author has given the geography and issues related to our discipline. We highlight three features in the works of Verne, in regard to geography: 1) The concern about the nature of geography and the role of the geographer. Having here our main contribution in this work, at this point, we will investigate these two concerns seem curiously uncommon among those that attract a fiction writer, as concern the history of geographical thought more specifically, 2) The impossible classification of his work in a particular school of Geographical Thought, 3) The situation of working within a "geography before the geography," but at the same time predict the birth of modern geography. We will further the work of Verne in two aspects: the science communicator and visionary. As a popularizer of geography that was in his time, the examples are many throughout his work and meet in the daily life of its characters. As a visionary, did not escape him even predicting the birth of modern geography. We can say that Jules Verne made science a living presence in all his works and found in the "real" geography sure to be writing about the greatest of human adventures - the conquest of Earth.
\end{abstract}

Keywords: Jules Verne. Geographical Thought. Literature and geography.

\section{La géographie dans l'oeuvre de Jules Verne: diffusion, tradition e la modernité}

Resumée - En n'utilisant que quelques-unes des oeuvres de Jules Verne à titre d'exemple, nous avons entre nos objectifs dans le présent document mettre en évidence certains thèmes, caractéristiques et éléments de la géographie chez Verne qui témoignent de la grande importance que cet auteur a donné à la géographie et aux questions liées à notre discipline. Nous mettons en évidence trois caractéristiques dans les œuvres de Verne, à l'égard de la géographie: 1) L'auteur etait préoccupé par la nature de la géographie et le rôle du géographe. En trouvant ici notre principale contribution dans ce travail, à ce moment, nous allons enquêter sur ces deux préoccupations qui semblent être curieusement rare parmi ceux qui attirent un auteur de fiction - il s'aggit du souci de l'histoire de la pensée géographique, plus précisément, 2) l'impossibilitée de classer son travail dans une école précise de la pensée géographique, 3) la situation de travailler au sein d'une "géographie avant la géographie», mais en même temps d'avoir prévu la naissance de la géographie moderne. Nous allons analiser le travail de Verne dans les deux aspects: le communicateur scientifique et le visionnaire. Comme un vulgarisateur de la géographie de son temps, les exemples sont nombreux tout au long de son travail et se rencontrent dans la vie quotidienne de ses personnages. Comme un visionnaire, n'a pas lui échapper même la prédiction de la naissance de la géographie moderne. Nous pouvons dire que Jules Verne fait de la science une présence vivante dans toutes ses œuvres et dans la "vraie" géographie il était sûr d'avoir écrit sur le plus grand des aventures de l'homme - la conquête de la Terre.

Mots-clées: Jules Verne. Pensée Geographique. Littérature et Géographie. 